\title{
Strongyloides stercoralis hyperinfection in an HIV positive patient
}

\author{
J N Harcourt-Webster, F Scaravilli, A H Darwish
}

\begin{abstract}
A 25 year old British man of previous good health presented with persistent generalised lymphadenopathy and was found to be human immunodeficiency virus (HIV) antibody positive. Three years later after weight loss and loose stools Strongyloides stercoralis was identified in the latter and successfully treated with thiabendazole. Shortly afterwards, a further episode again responded rapidly, but was swiftly followed by a final and fatal illness with severe debility and metabolic imbalance unresponsive to all treatment. Necropsy showed widespread and heavy strongyloidiasis with pulmonary haemorrhage, bronchopneumonia, and meningitis.
\end{abstract}

The nematode Strongyloides stercoralis, first described by Normand in $1876,{ }^{1}$ is especially associated with warm, wet climates where up to $85 \%$ of the population can be infected. ${ }^{2}$ The incidence is very much lower elsewhere, particularly in northern Europe.

Most healthy people are not susceptible to $S$ stercoralis infection but with debilitating disease of any sort, patients with immune based disorders managed by corticosteroids and those taking the drugs used in organ transplantation and cytotoxic regimens, susceptibility can increase. ${ }^{3}$ The common factor throughout is suppression of cell mediated immunity; infection may be direct, including as a result of homosexual contact, or may be a reactivation of clinically dormant disease.

The spread of AIDS in the early 1980s was followed by occasional reports of strongyloidiasis. ${ }^{4}$ In the United Kingdom the Communicable Disease Surveillance Centre reported a cumulative total of $14723 \mathrm{HIV}$ infected persons by October 1990 of whom 3798 had AIDS, but there is no report of an associated infection with $S$ stercoralis.

\section{Case report}

A previously healthy, slightly built, 25 year old British man presented in 1985 with persistent generalised lymphadenopathy; he was HIV seropositive (ELISA), but further investigation was declined. Early in 1988 he complained of weight loss and loose stools; $S$ stercoralis was identified in the latter and after treatment with thiabendazole (300 mg twice a day for three days) the nematode and the symptoms disappeared. Full blood count was normal.

Two months later there was a recurrence, again cleared by thiabendazole $(1.5 \mathrm{~g}$ twice a day for two days); on discharge the lymphocyte count was $0.42 \times 10^{9} / 1$, but the source of the infection remained unknown. After a month he was readmitted with central abdominal pain, bilious vomiting and constipation, weight loss, and for a short time backache and a near generalised papular skin rash.

He was drowsy and dehydrated with persistent generalised lymphadenopathy; the abdomen was diffusely tender, but bowel sounds were active. All other systems were normal. Laboratory results included haemoglobin $12 \cdot 7 \mathrm{~g} / \mathrm{dl}$, white cells were $12 \cdot 7$ $\times 10^{9} / 1$ with lymphocytes $0.40 \times 10^{9} / 1$, but no eosinophilia; urea concentration was 18.2 $\mathrm{mmol} / \mathrm{l}$. Despite antiemetics and intravenous fluids his fluid balance remained negative and the following day hyponatraemia $(116 \mathrm{mmol} / \mathrm{l})$ was increasing as were uraemia $(25.8 \mathrm{mmol} / \mathrm{l})$ and respiratory acidosis $\left(\mathrm{pH} 7 \cdot 15, \mathrm{pCO}_{2} 36 \cdot 4\right.$, $\mathrm{HCO}_{3}$ 13.1). Results of gastroscopy and aspiration were negative. Hours later he vomited copiously with cardiorespiratory arrest; his haemoglobin was $5 \cdot 3$, total white cell count $4.7 \times 10^{9} / 1$ (no differential) and a chest $x$ ray picture showed bilateral widespread shadowing. Despite ventilation, massive antibiotic and supportive treatment he died. No CD4 lymphocyte counts were done.

\section{Pathology}

At necropsy there was premature ageing with swelling of the upper neck and a dermal vasculitis as seen with severe bacterial infection, but no skin parasites. The stomach contained blood from elsewhere, but was otherwise normal. The small intestine was slightly distended with a lustreless serosa and thinned, inflamed walls; this and mucosal ulceration peaked in the ileum. A few rhabditiform stage $S$ stercoralis were seen in the intraluminal debris with adult female forms amid the crypts of both duodenal and jejunal mucosa (fig 1); ova and hatching larvae lay in their depths. Filariform larvae were deeper in the wall, being numerous in the proximal intestine, but fewer elsewhere. Parasites permeated lymphatics and venous sinusoids in the jejunum (fig 2), but not in the ileum. In the latter wall, however, all layers included foreign body type giant cells, singly and in clusters, usually engulfing degenerate Department of Histopathology, Westminster Hospital, 17 Horseferry Road, London SWIP 2AR

Accepted for publication 31 October 1990 
Figure 1 Adult female $S$ stercoralis coiled in crypts of the jejunal mucosa; bottom right is the buccal capsule, with centre ova both in the uterus and among adjacent mucosa (haematoxylin and eosin).
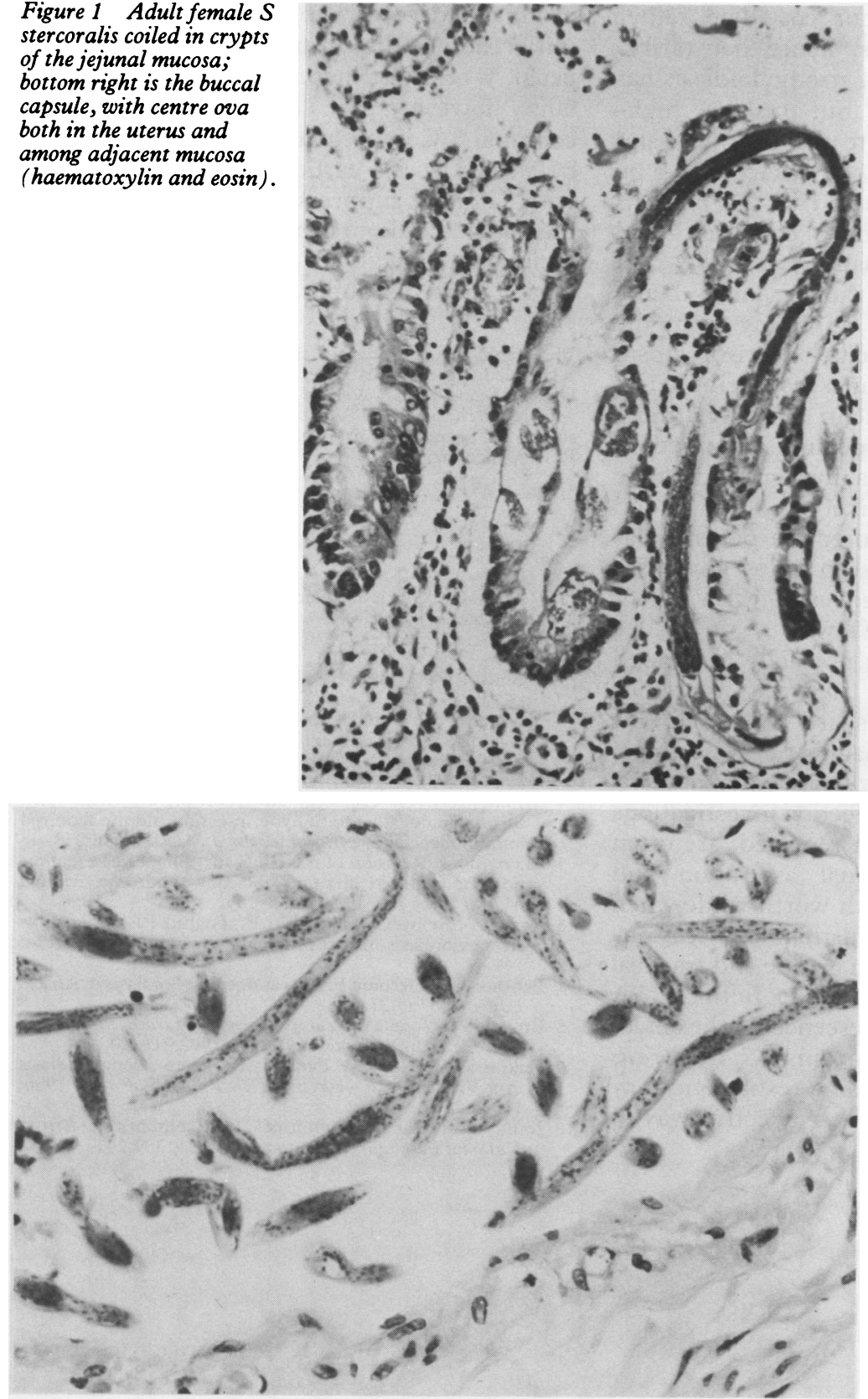

Figure 2 A nest of filariform larvae almost plugging a lymphatic in the wall of the jejunum; no local inflammation (haematoxylin and eosin).

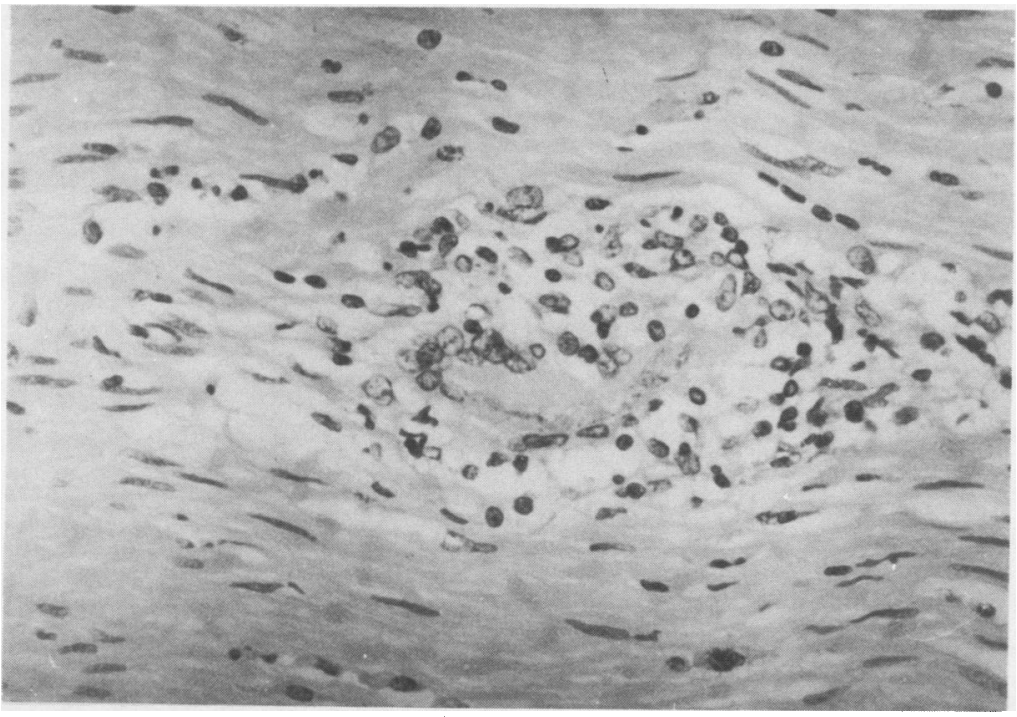

Figure 3 Foreign body type giant cells within the muscle of the small intestine, the cytoplasm of one containing the remains of a larva, creating a "tombstone" for partially removed strongyloides (haematoxylin and eosin). larvae (fig 3). The large intestine was universally slightly inflamed with fibrous thickening of the wall, but there was no evidence of infection or parasites.

Both lungs, the left weighing $1120 \mathrm{~g}$, the right $1240 \mathrm{~g}$, were uniformly firm with congestion and oedema and multiple zones of intraluminal mainly recent haemorrhage. Alveolar spaces, including subpleural ones, purulent exudate in bronchial lumina, and respiratory passage walls frequently showed the presence of $S$ stercoralis. Parasites permeated lymphatics and vascular sinusoids and again there were giant cells with parasite debris, usually in alveoli. There was early tracheitis with intraluminal bloody fluid and a lower lobe severe bronchopneumonia with occasional microabscesses and patchy fibrin pleurisy. The inflamed tissue was often accompanied by copious hyaline membrane, both in alveoli and their ducts. The tracheobronchial submucosa showed groups of giant cells, but no parasites, although they occurred alone amid collagen and nerves deeper in the wall.

A meningeal exudate with both granulocytes and small round cells covered both the convexity of the brain (1420 g) and the posterior fossa, sometimes involving the cortical blood vessels. The pituitary and softened upper spinal cord showed early necrosis, the dura and mainly the white matter of the latter being similarly inflamed; this was also evident in the eroding posterior border of the foramen magnum and through an erosion in the occipital bone with the soft tissues of the upper neck. No microglial nodules, multinucleated giant cells, granulomas or worms were seen.

Parasites were found in the capsule only of the spleen and in the peripheral sinus and paracortex of cervical and para-aortic lymph nodes with additional disease in perinodal tissue, vessels, and nerve bundles elsewhere.

The heart $(320 \mathrm{~g})$ and other tissues were essentially normal.

All microbiological cultures were negative and no cytomegalovirus inclusion bodies, fungi or bacilli of any type were seen anywhere.

\section{Discussion}

HIV infection has been recognised in the United Kingdom since 1981 , but as far as we know this is the first death from $S$ stercoralis reported in such a patient. The Centers for Disease Control included extra-intestinal strongyloidiasis in the original classification of opportunistic infections associated with AIDS, but this was later deleted, ${ }^{5}$ only a few such combinations having been recorded. ${ }^{4}$

$S$ stercoralis is rare and only occasionally transmitted in the United Kingdom, ${ }^{6}$ the source of the helminth usually being unknown. Contact is probably followed by latent chronic infection which only becomes clinically important with immunosuppression. We believe that this suppression evidenced by depleted lymphocytes and induced by HIV infection, occurred in this case and precipitated hyperinfective strongyloidiasis. The impairment of cell mediated immunity arising in this particular 
way, however, may favour coccidian rather than helminthic infections, ${ }^{7}$ hence their rarity.

The pathophysiology of strongyloidiasis has been well documented, ${ }^{23}$ but this case highlights the changes leading to malabsorption and impaired lung function, both exacerbated by nerve plexus disease. Spread to the brain is rare, ${ }^{3}$ but better known is an often fatal purulent meningitis, usually Escherichia coli, part of a bacteraemia, the organism being carried by the helminth migrating from the intestine ${ }^{8}$ Here the failure to culture organism from the brain, or the lungs, is attributed to massive antibiotic treatment; moreover, there was no evidence of any opportunistic infection.

Whenever larvae die a foreign body type giant cell granuloma is likely to develop and remain as a tombstone after the parasite has disappeared. This can be seen almost anywhere as happened before the advent of HIV infection, although reports are few.

Worm infestations are normally associated with eosinophilia, but in the immunocompromised eosinophils are depressed like lymphocytes and this diagnostic indicator is unavailable. With scanty larvae diagnosis is difficult, but with hyperinfection investigations of faeces, especially when repeated, are often successful, while duodenal aspiration and endoscopic biopsy are both worth while when an invasive procedure is justifiable. Occasionally the helminth is seen in gastric and tracheal aspirates, pleural fluid, and urine. ${ }^{3}$ Both ELISA and indirect immunofluorescence for the detection of IgG antibodies against $S$ stercoralis antigen have given promising results and may represent a sensitive and cost effective way of detecting such infections. ${ }^{9}$
Thiabendazole is the drug of choice, and initial therapeutic control, as in this patient, is usual. Worms are increasingly becoming resistant, however; side effects are also more common. ${ }^{10}$ Comprehensive treatment needs to be started at the earliest stage, but any drug with immunosuppressive effects is contraindicated. The course of this patient illustrates vividly the difficulty of controlling an infection arising in the immunocompromised.

We thank $\mathrm{Dr} R$ A Parkin for permission to publish and acknowledge the invaluable technical assistance of Messrs A J acknowledge the invaluable technical assistance of Messrs A Hall, P Mooney, and D Webber, of Mrs K Burnett for assistance
with research, and Mrs A Martinez for preparing the manuwith research, and Mrs A Martinez for preparing the manu-
script. Dr Scaravilli is grateful for a grant from the Medical

script. Dr Scaravill
Research Council.

1 Normand L. Sur la maladie dite diarrhée de Cochinchine. Comptes Rendus Hebdomadaires des Séances de l'Académie des Sciences (Paris) 1876;83:316-18.

2 Meyers WM, Connor DH, Neafie RC. Strongyloidiasis. In: Binford CH, Connor DH, eds. Pathology of tropical and extraordinary diseases. Washington, DC: Armed Forces extraordinary diseases. Washington,

3 Grove DI. Clinical manifestations. In: Grove DI, ed Strongyloidiasis: $A$ major roundworm infection of man. London: Taylor and Francis, 1989:155-73.

4 Armingnacco O, Capecchi A, De Mori P, Grillo LR. Strongyloides stercoralis hyperinfection and the acquired immunodeficiency syndrome. Am J Med 1989;86:258.

5 Anonymous. Revision of the CDC surveillance case definition for acquired immunodeficiency syndrome. Morbid Mortal Week Rep 1987;36:3S-155.

6 Sprott V, Selby CD, Ispahani P, Toghill PJ. Indigenous strongyloidiasis in Nottingham. Br Med J 1987;294: $741-2$.

7 Petithory JC, Derouin F. Aids and strongyloidiasis in Africa. Lancet 1987; i:921.

8 Brown WJ, Voge M. Neuropathology of parasitic infections. Oxford: Oxford University Press, 1982:218-20.

9 Hakim SZ, Genta RM. Fatal disseminated strongyloidiasis in a Vietnam war veteran. Arch Pathol Lab Med 1986; 110:809-12.

10 Joint Formulary Committee. Antihelmintics. British National Formulary. London: HMSO, 1989:241 